\title{
Effect of Accumulative Strain on Grain Refinement and Strengthening of ZM6 Magnesium Alloy During Continuous Variable Cross-Section Direct Extrusion
}

\author{
Feng Li $\cdot$ Wei Shi $\cdot$ Nan Bian $\cdot$ Hong-Bin Wu
}

Received: 26 September 2014/Revised: 21 November 2014/Published online: 4 March 2015

(C) The Chinese Society for Metals and Springer-Verlag Berlin Heidelberg 2015

\begin{abstract}
In order to study the influence of die combination on continuous variable cross-section direct extrusion (CVCDE) in the extrusion process, the accumulative strain formula is derived, and it can be known that the extrusion ratio of various stages directly determines the size of corresponding stage strain by formula. In this paper, as an example of the two interim dies, three die combinations of different angles and extrusion ratio are designed. Aviation magnesium alloy ZM6 is studied, and the results show that dynamic recrystallization is even more complete when continuous shear deformation occurs, so that the refinement and homogenization of microstructure are obtained. By the use of different die combinations, the accumulative strain increases under the conditions of same total extrusion ratio. Thus, the refined crystalline strengthening effect of extrusion deformation can be further analyzed. Due to the dead-zone defects, the actual accumulative strain decreases significantly and the effect of microstructure and performance improvements also decreases with it. Therefore, the optimal design of die combination is the key to the process and product of CVCDE, which provides a scientific basis for the development of severe plastic deformation.
\end{abstract}

KEY WORDS: Continuous variable cross-section direct extrusion (CVCDE); Die combination; Accumulative strain; Magnesium alloys; Severe plastic deformation

\section{Introduction}

Magnesium and magnesium alloys are the lightest metal structure material in engineering application, and due to a series of excellent properties, it has been favored in the areas of aerospace, transportation and equipment manufacture [1]. But the lattice structure of hexagonally close-packed magnesium alloy determines its poorer plastic-forming ability and lower strength at room temperature. According to the Hall-Patch formula, when grain refinement reaches to a certain extent, the prismatic glide and

Available online at http://link.springer.com/journal/40195

F. Li $(\bowtie) \cdot$ W. Shi $\cdot$ N. Bian $\cdot$ H.-B. Wu

School of Materials Science and Engineering, Harbin University

of Science and Technology, Harbin 150040, China

e-mail: fli@hrbust.edu.cn; hitlif@126.com even pyramidal glide can be activated and therefore improve the plastic deformation ability, while increasing the strength and toughness [2]. Compared with the modification, rapid solidification, powder alloying and semisolid processing, the severe plastic deformation technology can easily acquire the ultrafine-grain structure and the excellent mechanical properties, due to its unique stress state and the larger accumulative strain [3-5]. In recent years, the severe plastic technology has received a lot of attribution by scholars, developed rapidly and widely used in the study of the high-performance magnesium alloy preparation [6].

Zhao et al. [7] found that the microstructure was effectively refined, and the mechanical properties were improved with numbers of equal-channel angular pressing (ECAP) passes increasing from one pass to four passes. However, strengths decreased slightly after five passes though the grain size decreased considerably; Akbaripanah et al. [8] have studied AM60 magnesium alloy by ECAP, 
and the results show that the grain size was decreased from 19.2 to $2.3 \mu \mathrm{m}$ after six passes at $473 \mathrm{~K}$.

It was found that the microstructure was effectively refined by equal-channel angular pressing (ECAP) and the highpressure torsion (HPT) was used for the research of high performance magnesium alloy preparation. Serre et al. [9] have processed AZ31 magnesium alloy by HPT through 5 turns at $453 \mathrm{~K}$; the size of the grains obtained in HPT was $0.5 \mu \mathrm{m}$, and there was less dependence on local strain rate of hardness and average grain size was proved Kawasaki et al. [10] also studied the AZ31 magnesium alloy processed by HPT, and the results show that the microhardness had a significant difference between 296 and $463 \mathrm{~K}$ in different turns.

A lot of cyclic extrusion and compression (CEC) researches are carried out by domestic scholars. Wang et al. $[11,12]$ have studied AZ31 magnesium alloy processed by CEC, and the results show that CEC is an effective method for grain refinement of magnesium alloy; the most effective CEC pass is the first pass. However, the homogeneity of the microstructure is almost constant after three passes.

In addition, the simple shear extrusion (SSE) [13], repetitive forging (RF) [14] and repetitive extrusion and upsetting (REU) [15], which preparation technology of high performance metal have emerged and been applied. However, all of them have some shortcomings of the cumbersome process and the poor uniformity due to the process characteristics. Therefore, CVCDE proposed by authors in this paper can solve the above problems. In this paper, the flow behavior and microstructure were studied through the different accumulative strains obtained by different interim die combinations.

\section{Experimental}

As shown in Fig. 1, CVCDE is the technology which adds some interim dies between the billet and the die according to the research requirements. And a channel with continuous variable cross-section is composed of interim dies and die. The billet is subjected to continuous shear deformation in the extrusion process, and the accumulative strain increase is reached in a single pass. Thus, CVCDE reached the purpose of depth modified for the extruded products.

In this study, the inside diameter of the container was $40 \mathrm{~mm}$ and the diameter of die was $6 \mathrm{~mm}$. The extrusion ratio was 44.4 theoretically. The different number and structure of interim die can compose various combinations. It had a crucial influence on extrusion process. To be convenient for contrastive analysis, only the combination of two-stage interim dies was studied in this work. The parameters are shown in Table 1 , and the specific location of the parameters in Table 1 is shown in Fig. $1 \mathrm{~b}$.

It can be seen from Table 1 that the various stages of plans 1 and 2 have the same extrusion ratio, but the die angles are different. The influence of die angle in the forming process can be studied by plans 1 and 2 . The die angles of plans 2 and 3 are the same, but the extrusion ratio of various stages are different. The influence of accumulative strain in the forming process can be studied by the plans 2 and 3 .

For studying the important influence of the die combination on the material flow behavior, the simulation software DEFORM-2D was used.

The aviation heat-resisted magnesium alloy ZM6 with original size of $\Phi 40 \mathrm{~mm} \times 50 \mathrm{~mm}$ was employed, and chemical composition of it is given in Table 2. The extrusion temperature and the extrusion speed were $450{ }^{\circ} \mathrm{C}$ and $1 \mathrm{~mm} / \mathrm{s}$, respectively, and the used lubricant was water-based graphite. The samples were split at the typical locations of extrusion products, as shown in Fig. 2. The cross-sections of the samples were polished to a mirror finish and etched by the solution containing $1 \mathrm{~mL}$ acetic acid, $1 \mathrm{~mL}$ concentrated nitric acid, $1 \mathrm{~g}$ oxalic acid and $150 \mathrm{~mL} \mathrm{H}_{2} \mathrm{O}$, and then observed using a OLYMPUS-
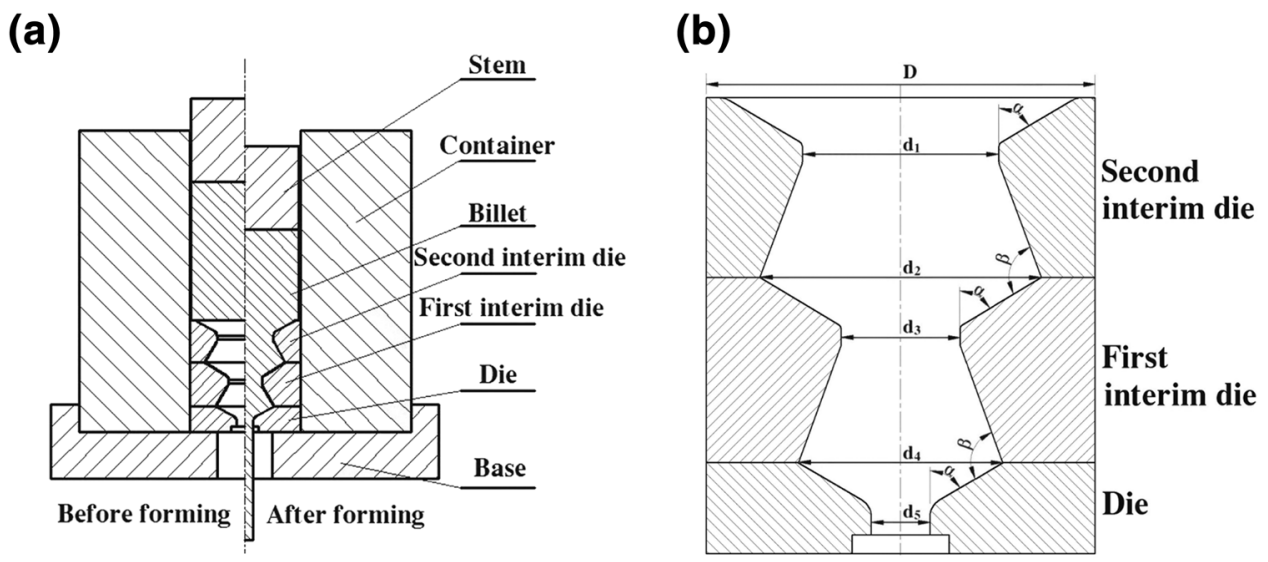

Fig. 1 Schematic of CVCDE: a schematic of forming, b structure of the die and the interim dies 
Table 1 Parameters of the different plans in the experiment

\begin{tabular}{lllllllll}
\hline Plan & $D(\mathrm{~mm})$ & $d_{1}(\mathrm{~mm})$ & $d_{2}(\mathrm{~mm})$ & $d_{3}(\mathrm{~mm})$ & $d_{4}(\mathrm{~mm})$ & $d_{5}(\mathrm{~mm})$ & $\alpha$ & $\beta$ \\
\hline Plan 1 & 40 & 20 & 28 & 12 & 20 & 6 & $60^{\circ}$ & $100^{\circ}$ \\
Plan 2 & 40 & 20 & 28 & 12 & 20 & 6 & $40^{\circ}$ & $120^{\circ}$ \\
Plan 3 & 40 & 20 & 28 & 16 & 6 & $40^{\circ}$ & $120^{\circ}$ \\
\hline
\end{tabular}

Table 2 Chemical compositions (wt $\%$ ) of ZM6 used in the experiment

\begin{tabular}{lllllll}
\hline $\mathrm{Zn}$ & $\mathrm{Zr}$ & $\mathrm{Nd}$ & $\mathrm{Cu}$ & $\mathrm{Ni}$ & Impurity & $\mathrm{Mg}$ \\
\hline $0.2-0.7$ & $0.4-1.0$ & $2.0-2.8$ & $\leq 0.1$ & $\leq 0.01$ & $\leq 0.30$ & Margin \\
\hline
\end{tabular}

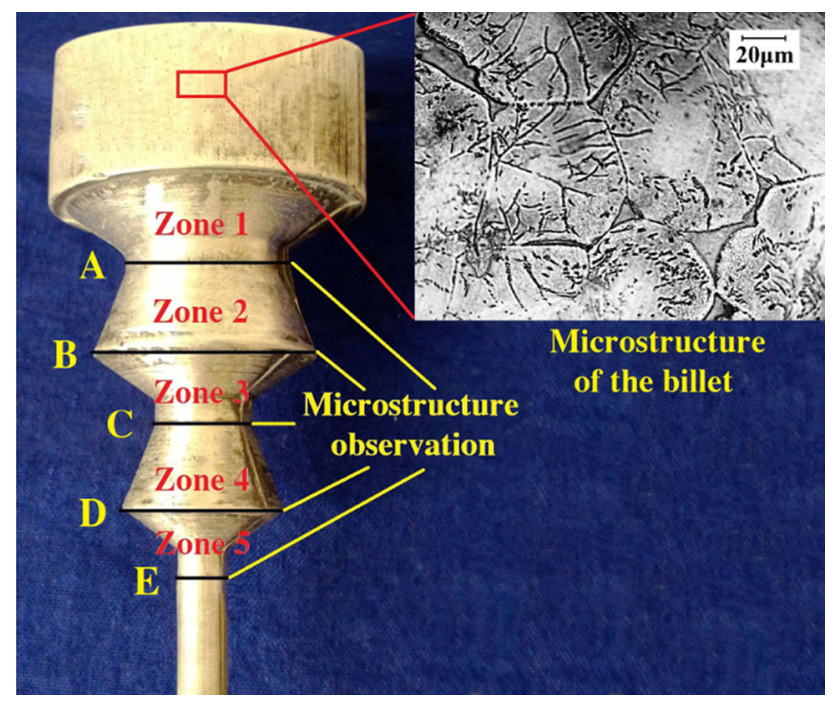

Fig. 2 Microstructure of billet and sample positions

GX71-6230A metallographic microscope. The tensile tests were performed using the $100 \mathrm{KN}$ CSS-44300 universal test device, and the crosshead speed is $3 \mathrm{~mm} / \mathrm{min}$. The morphology of the tensile fracture was observed by the S-570/ HITACHI-4700 scanning electron microscope (SEM).

\section{Discussion and Analysis}

\subsection{Accumulative Strain}

The continuously changed cavity shape can change accumulative strain under the fixed extrusion ratio condition. The die combination of different quantity and structure has important influence on the accumulative strain, and the formula of the accumulative strain is derived under the following assumptions: (1) The material is continuous and homogeneous during extrusion; (2) no matter how complex of the cavity, assuming that the entire process without dead zone.

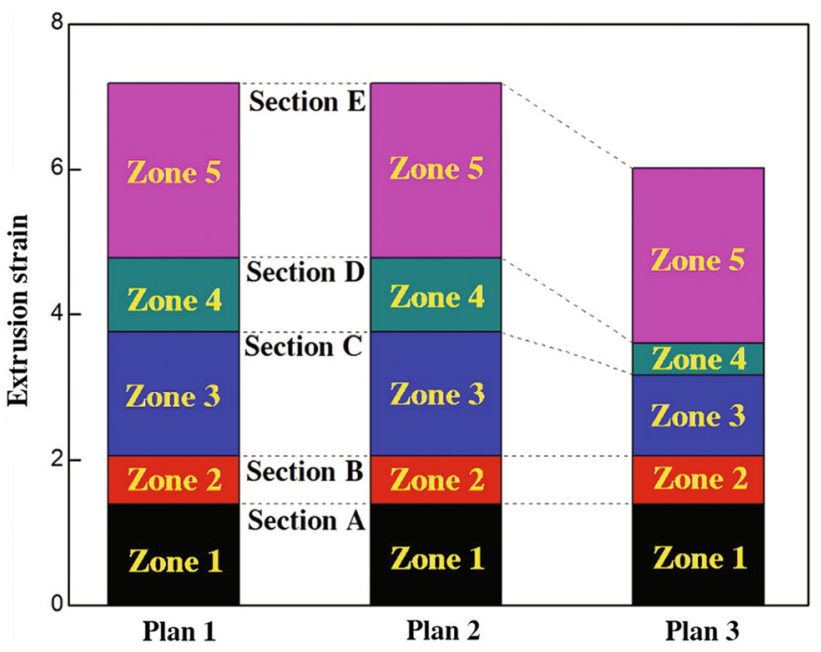

Fig. 3 Cumulative strain under different plans

The accumulative strain of conventional extrusion and upsetting is expressed by the following equation [16]:

$\varepsilon=\ln \frac{D^{2}}{d^{2}}=2 \ln \frac{D}{d}$,

where $D$ is the cavity diameter of the entry side and $d$ is the exit side.

The material flows from top to bottom successively by extrusion. Set $D, d_{1}, d_{2}, d_{3}, d_{4}$ and $d_{5}$ as the diameter of continuous variable cross-sections as shown in Fig. 1b. When the material flows through zone 1, Eq. (1) can be written as

$\varepsilon_{1}=\ln \frac{D^{2}}{d_{1}^{2}}=2 \ln \frac{D}{d_{1}}$.

When the material flows through the zone 2, upsetting deformation occurs and Eq. (1) should be written as

$\varepsilon_{2}=-\ln \frac{d_{1}^{2}}{d_{2}^{2}}=2 \ln \frac{d_{2}}{d_{1}}$,

Similarly, when the material flows through the zone 3-5, the strains can be expressed by the following equations:

$\varepsilon_{3}=\ln \frac{d_{2}^{2}}{d_{3}^{2}}=2 \ln \frac{d_{2}}{d_{3}}$,

$\varepsilon_{4}=-\ln \frac{d_{3}^{2}}{d_{4}^{2}}=2 \ln \frac{d_{4}}{d_{3}}$, 

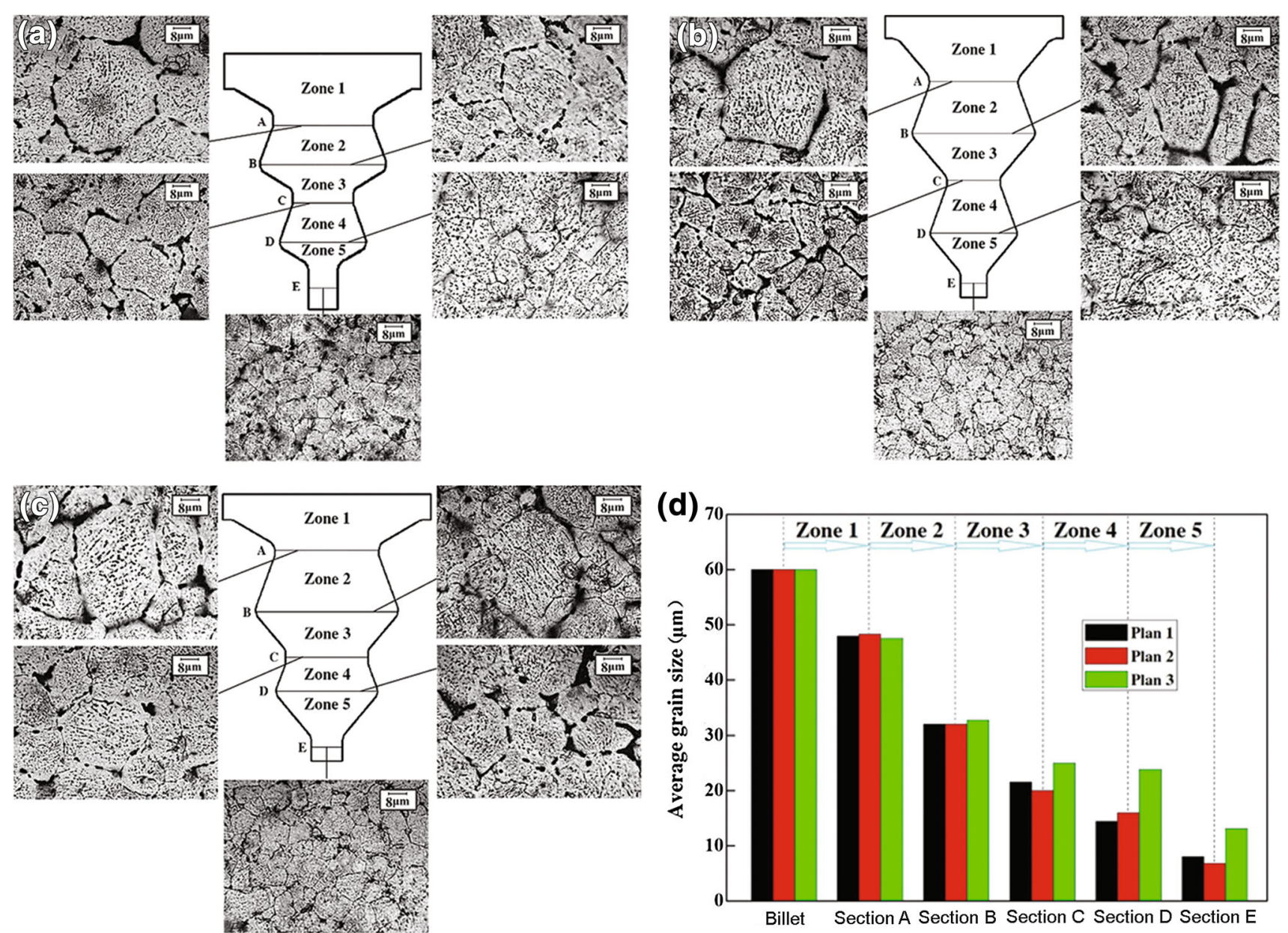

Fig. 4 Microstructures of the samples extruded under different plans: a plan 1, b plan 2, c plan 3, d the average grain size

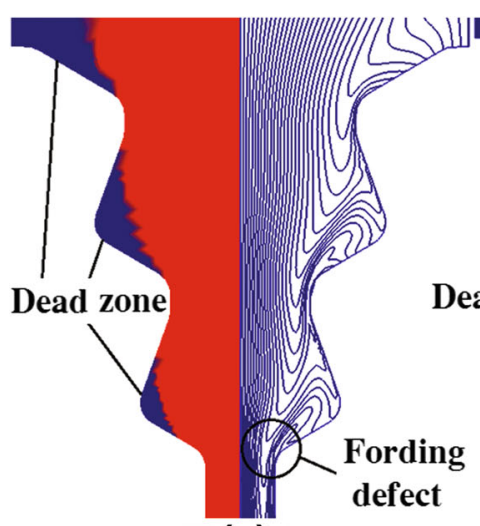

(a)

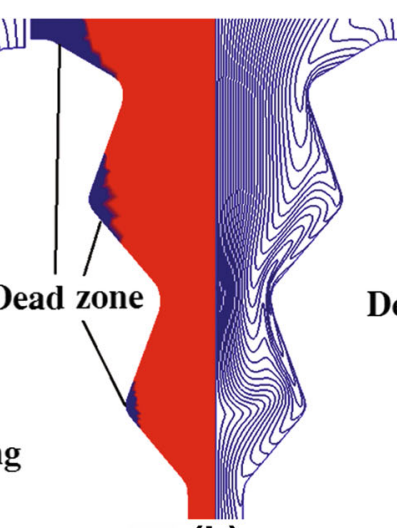

(b)

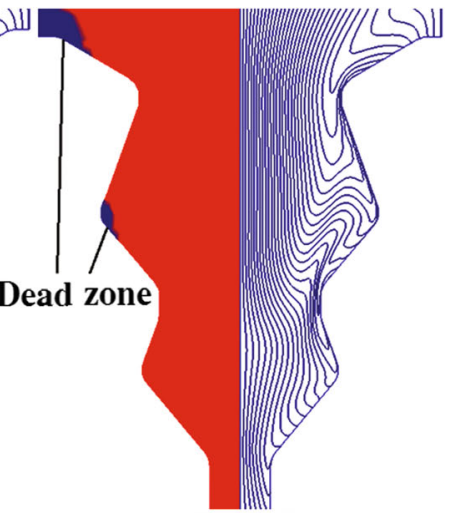

(c)

Fig. 5 Dead zone and the streamline distribution under different plans: a plan 1, b plan 2, c plan 3 


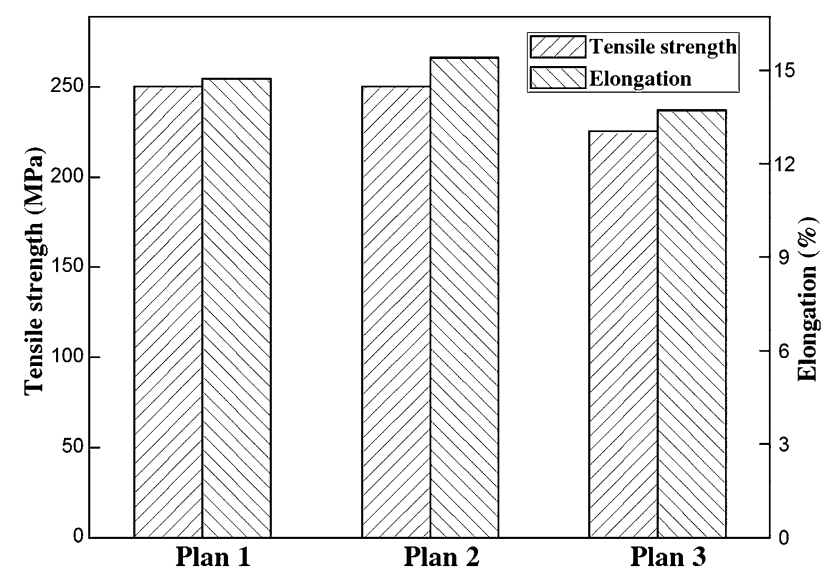

Fig. 6 Mechanical properties under different plans

$\varepsilon_{5}=\ln \frac{d_{4}^{2}}{d_{5}^{2}}=2 \ln \frac{d_{4}}{d_{5}}$

The accumulative strain, $\varepsilon_{\text {total }}$, can be derived from Eqs. (2)-(6):

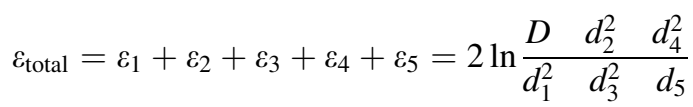

$$
\begin{aligned}
& =2 \ln \frac{D}{d_{5}}+4 \ln \frac{d_{2} \quad d_{4}}{d_{1} \quad d_{3}} .
\end{aligned}
$$

On the basis of Eq. (7), the universal theoretical accumulative strain of CVCDE can be derived as:

$n=2 N+1$,

$\varepsilon=2 \ln \frac{D}{d_{n}}+4 \ln \frac{\prod_{i=1}^{n} d_{2 i}}{\prod_{i=1}^{n} d_{2 i-1}} \quad(i=1,2,3 \ldots)$,

where $n$ is the number of the zones and $N$ is the number of interim dies.

The strain of various stages can be derived from Eq. (9), as shown in Fig. 3. It can be seen that the strains of plan 1 and plan 2 are completely the same, while the strains of zone 3 and zone 4 of plan 3 are less than those of plans 1 and 2. Therefore, from the theoretical point of view, the strain of variable stages is related to the extrusion ratio except die angles.

\subsection{Microstructure Evolution}

The billet flows from zones 1 to 5 successively along the loading direction of stem, and the microstructures of that changed continually. The different structure and combinations of interim dies present a different change on the strain and have an important influence on the evolution of organizations. The comparisons of the microstructure and the grain size at the position of each cross-section (section A, B, C, D, E) during the stationary extrusion are shown in Fig. 4.

As shown in Fig. 4a-c, continuous shear deformation of the material occurs during extrusion process, and they have a process of the grain refinement. The intermetallic compound is crushed significantly and distributed in the matrix uniformly. Compared with the original cast coarse-grain structure, the material dynamic recrystallization occurs adequately by CVCDE, and the level of the grain refinement and uniformity has been further improved.

The grain size of the original billet is $60 \mu \mathrm{m}$ as shown in Fig. 2. The comparison of grain size with different plans is also shown in Fig. 4. It can be seen from the numerical values that the grain size decreases gradually in the extrusion process. Among them, due to the strains of various stages of plans 1 and 2 are same, the variation trends of corresponding microstructure in the various stages are quite similar. The final grain sizes of them are 8.0 and $6.8 \mu \mathrm{m}$, respectively. Although the strain is an important factor in determining the grain size, the die-angle change causes the different flow properties of the material. And this different causes the formation of different degree dead zone $\mathrm{f}$ in the continuous variable channel. The material cannot acquire the perfect effect when shear deformation occurs; therefore, the actual accumulative strain is less than the perfect state. The grain size of plan 3 is similar to the first two before cross-section B. The grains show a fine trend gradually; however, they are coarser than plans 1 and
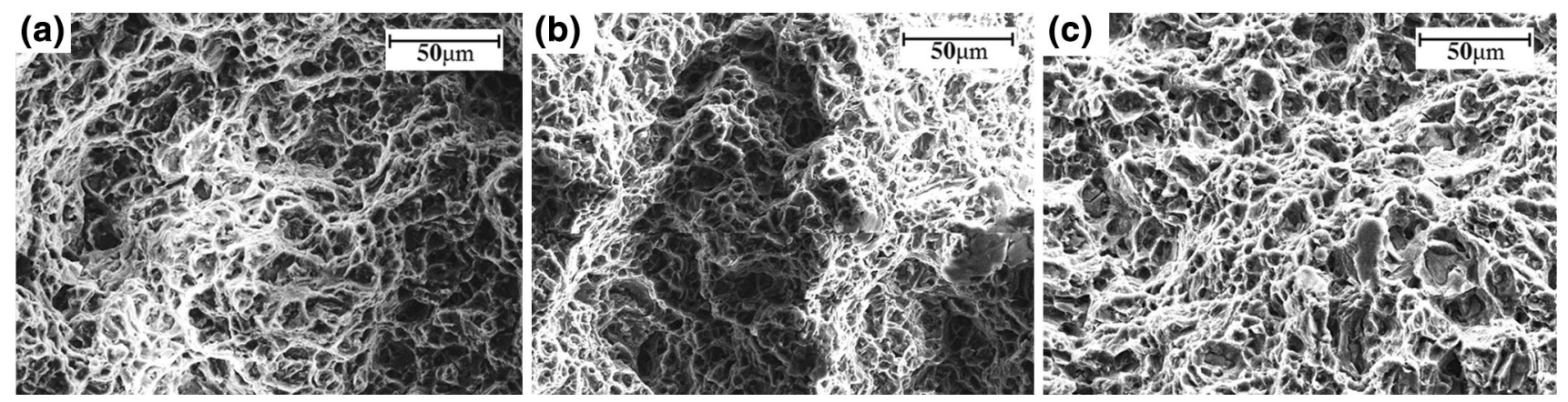

Fig. 7 Fracture morphologies of the tensile samples under different plans: a plan 1, b plan 2, c plan 3 
2 in each section after cross-section B. The $d_{3}$ (section C) of plan 3 is greater than the first two, and the accumulative strain of plan 3 is smaller (shown in Fig. 3); thus, less energy is provided, and the degree of dynamic recrystallization is smaller. The degree of grain refinement is smaller than the first two, and its specific performance is coarse grains.

From the foregoing analysis, the theoretical calculation of the accumulative strain is based on the original size of cavity corresponding diameter. However, due to dead zone, the accumulative strains of plans 1 and 2 decreases in varying degrees. Compared with plan 2 , the distortional degree of plan 1 is larger than that of others. This is the reason why they both have a same strain, but the microstructure is different after forming.

\subsection{Flow Uniformity}

The die combination has important influence on the material flow behavior. When the stroke of the stem is $20 \mathrm{~mm}$, the plastic zone morphology and the streamline distribution are shown in Fig. 5.

As shown in Fig. 5, when the cavity changes, the zone scope that satisfies plastic yield condition also changes. And the flow behavior presents a difference. It can be seen from Fig. 5a that there are many zones (the dead zone) which are difficult to be extruded out inside the cavity of plan 1 . The curved degree of streamline distribution is very serious, and finally, it forms folding defect at the die orifice. When using the cavity structure of the plan 2, the scope of the dead zones is significantly reduced at the same site of the former, and the plastic yield zone is extended, as shown in Fig. 5b. There is a significantly large angle bend and folding trend near the outer part of the cavity, but the curved streamline is gradually straighten out along the axial direction during extrusion, and no folding defects formation. As shown in Fig. 5c, the scope of dead zone of plan 3 is very small; thus, the material in the cavity almost reaches the yield condition, and plastic deformation occurs. The streamline in the cavity substantially is parallel to the extrusion direction, and the flow uniformity improved significantly.

\subsection{Tensile Properties and Fracture Morphology}

The tensile strength and elongation in different plans are shown in Fig. 6. Compared with plan 1, the various stage strains of plan 2 are the same. The die angles are different, and they are $60^{\circ}$ and $40^{\circ}$, respectively. The results show that the tensile strengths of the both are $250 \mathrm{MPa}$, but the elongation increases from $14.4 \%$ to $16.0 \%$. Compared with plan 2, the die angles are the same, but the accumulative strain reduces from 7.2 to 6.0 . Compared with plan 2 , the tensile strength reduces of plan 3 from $250 \mathrm{MPa}$ to 225 $\mathrm{Mpa}$, and the elongation reduces from $16.0 \%$ to $13.8 \%$, the decreasing amplitudes are $10 \%$ and $13.8 \%$, respectively.

Based on the above analysis, the increase in accumulative strain can improve the effect of the grain refinement of ZM6 magnesium alloy; thus, the mechanical properties are improved. The above results further prove that the accumulative strain has a significant impact on the development of the tensile strength and the elongation in extrusion process, and the influence of die angle is not obvious.

Figure 7 shows the fracture morphologies of the tensile samples under different plans. It can be seen that there are lots of dimples on the fracture surface of all the samples, and fracture occurs mainly along the grain boundaries. The main fracture mechanism is ductile fracture. The average dimple size and depth of them are very similar. However, the undulation on the fracture surface is different. Among them, the undulation of plan 2 is the largest as shown in Fig. 7b, followed by plan 1 (shown in Fig. 7a), and plan 3 is very smooth (shown in Fig. 7c). From the theoretical analysis, the sample with the larger undulation requires more energy to be fractured, and it is not easy to break under the same tension condition. Therefore, the tensile strength and elongation of the sample are improved. It is entirely consistent with the variation rule of the mechanical properties of corresponding plan.

\section{Conclusions}

(1) The accumulative strain model that is suitable for continuous variable cross-section direct extrusion is derived through theoretical derivation. Through the analysis, local or accumulative strain has a direct relation with extrusion ratio on the corresponding stages and has no relation with the die angle. The change of the die angle can alter the distribution of shear stress and cause the difference of microstructure and properties.

(2) The comparison of the results show that the accumulative strain can be increased from 6.0 to 7.2 through adjustment of die combination. The average grain size decreases from 13.1 to $6.8-8.0 \mu \mathrm{m}$. The degrees of rounding and uniformity are improved, and the tensile strength and elongation also increase simultaneously.

(3) When the design of die structure and size are unreasonable, the dead zone and streamline fording appeared on the lateral corner in the cavity of continuous variable cross-section. The dead zones cause the decrease in the accumulative strain in the corresponding position. The principle of die design is increasing the accumulative strain as much as possible under the conditions of no extrusion defect. 
Acknowledgments This work was financially supported by the National Natural Science Foundation of China (No. 51205094).

\section{References}

[1] G.H. Wu, M. Xie, C.Q. Zhai, X.Q. Zeng, Y.P. Zhu, W.J. Ding, Trans. Nonferrous Met. Soc. China 13, 1260 (2003)

[2] R.Z. Valiev, R.K. Islamgaliev, I.V. Alexandrov, Prog. Mater Sci. 45, 103 (2000)

[3] I.A. Anyanwu, Y. Gokan, A. Suzuki, S. Kamado, Y. Kojima, S. Takeda, T. Ishida, Mater. Sci. Eng., A 380, 93 (2004)

[4] H.L. Zhao, S.K. Guan, F.Y. Zheng, Q.K. Li, L.G. Wang, Trans. Nonferrous Met. Soc. China 15, 144 (2005)

[5] Z.D. Zhao, Q. Chen, H.Y. Chao, S.H. Huang, Mater. Des. 31, $1906(2010)$

[6] Q. Chen, J. Lin, D.Y. Shu, C.K. Hu, Z.D. Zhao, F. Kang, S.H. Huang, B.G. Yuan, Mater. Sci. Eng., A 554, 129 (2012)
[7] Z.D. Zhao, Q. Chen, H.Y. Chao, C.K. Hu, S.H. Huang, Mater. Des. 32, 575 (2011)

[8] F. Akbaripanah, F. Fereshteh-saniee, R. Mahmudi, H.K. Kim, Mater. Des. 43, 31 (2013)

[9] P. Serre, R.B. Figueiredo, G. Nong, T.G. Langdon, Mater. Sci. Eng., A 528, 3601 (2011)

[10] M. Kawasaki, R.B. Figueiredo, T.G. Langdon, J. Mater. Sci. 47, 7719 (2012)

[11] Y.J. Chen, Q.D. Wang, H.J. Roven, M.P. Liu, M. Karlsen, Y.D. Yu, J. Hjelen, Scr. Mater. 58, 311 (2008)

[12] Q.D. Wang, Y.J. Chen, M.P. Liu, J.B. Lin, H.J. Roven, Mater. Sci. Eng., A 527, 2265 (2010)

[13] N. Pardis, R. Ebrahimi, Mater. Sci. Eng., A 527, 355 (2009)

[14] A. Babaei, G. Faraji, M.M. Mashhadi, M. Hamdi, Mater. Sci. Eng., A 558, 150 (2012)

[15] L. Zaharia, R. Comaneci, R. Chelariu, D. Luca, Mater. Sci. Eng., A 595, 135 (2014)

[16] J. Richert, M. Richert, Aluminum 62, 604 (1986) 